\title{
The thermo-oxidative stability and flammability of wood/polypropylene composites
}

\author{
Slawomir Borysiak
}

Received: 1 October 2014/ Accepted: 4 December 2014/Published online: 27 December 2014

(C) The Author(s) 2014. This article is published with open access at Springerlink.com

\begin{abstract}
The main aim of the study was to evaluate the thermo-oxidative stability and flammability of wood/polypropylene composites. The composites were obtained by extrusion and compression moulding with chemical modification of wood in order to improve adhesion. The composites were characterised by differential scanning calorimetry and cone calorimetry, providing such parameters as the oxidation induction time and a few parameters describing flammability, e.g. time to ignition, heat release rate, mass loss rate, heat of combustion, specific extinction area and emission of toxic gases. The results illustrate a considerable effect of the presence of wood and chemical modifications of lignocellulosic filler on the thermo-oxidative stability and character of combustion of the composites studied. The information provided in the paper contributes towards the correct choice of chemical modification of wood that would improve mechanical properties of the composites and towards getting composite materials of target thermo-oxidative stability and flammability.
\end{abstract}

Keywords Polypropylene - Wood - Composites · Thermo-oxidative stability $\cdot$ Flammability

\section{Introduction}

Composites of polymers with lignocellulosics have been recently given much attention [1-6]. The interest in these materials stems from specific properties of renewable

\section{S. Borysiak $(\square)$}

Institute of Chemical Technology and Engineering, Poznan

University of Technology, Berdychowo 4, 60-965 Poznan,

Poland

e-mail: Slawomir.Borysiak@ put.poznan.pl cellulosic fibres used as a filler of plastics. As follows from literature [7-12], the key problem in producing composite materials is a poor interphase adhesion between the polymer matrix and the lignocellulose filler, which show a tendency towards aggregation and poor dispersion of the filler in the polymer matrix as well as deterioration of the mechanical properties of the product [13, 14]. For this reason, many authors have been searching for methods of chemical or physical modifications of the components [7-12, 15-18]. The modifiers employed include acid anhydrides, benzyl chloride, alkali solution, hexanediol diacrylate, hydroxyethyl methacrylate, diisocyanates and silanes, and are responsible for the improvement of mechanical properties and dimensional stability of composites. The modification described in detail by Thakur et al. [19-21] is free radical-induced graft copolymerisation of lignocellulosic materials and synthesis of graft copolymers from natural cellulose fillers under microwave conditions $[22,23]$. The grafted copolymers characterised increased chemical resistance and higher thermal stability. Another procedure aimed at improvement of adhesion is functionalization of hydrophobic polypropylene with hydrophilic modifiers in the presence of plasma [24].

Modification of the filler is also responsible for changing its nucleation abilities leading to changes in the interactions between the filler and the polymer matrix. According to some authors [25-30], chemical modification of the filler leads to a decrease in its nucleation abilities, while according to others $[31,32]$, it leads to an increase in the filler nucleation ability. An important problem in the context of determination of nucleation ability of lignocellulosic fillers can be the polymorphism of cellulose contained in the natural fillers. It should be added that mercerisation (treatment in sodium hydroxide) is responsible for the formation of another polymorphic variety of cellulose 
(cellulose II), which has been described in [33-35]. That is why the process of mercerisation responsible for the appearance of cellulose polymorphic forms deserves close analysis.

Much less attention has been devoted to a comprehensive analysis of thermo-oxidative stability of the composite materials. The effective use of wood-based particles as fillers or reinforcements in the thermoplastic polymers requires a fundamental understanding of the stability of the composite materials. The majority of lignocellulosic fillers have low degradation temperatures $\left(\sim 200{ }^{\circ} \mathrm{C}\right)$, which make them inadequate for processing with thermoplastics with processing temperatures above $200{ }^{\circ} \mathrm{C}$ [36-38]. Decomposition of wood components, such as cellulose and lignin creates voids inside the composite, causing reduction of the mechanical properties [39]. In general, it has been shown that in order to estimate the thermo-oxidative stability of the composite materials, it is necessary to take into account the oxidation induction time (OIT) [40-42]. OIT values depend on factors such as density, temperature, physical and chemical properties of polymer, type and amount of cellulosic fillers [38]. However, analysis of literature data has revealed many controversies; often the use of the same modifications of the lignocellulose component would bring different results. Araujo et al. [43, 44] showed that the lignocellulosic materials do not influence the oxidative thermal stability of the composites under isothermal conditions. Moreover, no effect or even a negative effect of compatibilization process of lignocellulosic fillers on thermal stability has been reported in other studies. Sharkh et al. presented [36] that the compatibilized date palm fibre/polypropylene composites are generally less stable than uncompatibilized ones as a result of the lower stability of the maleated polypropylene. Pukanszky [45] claimed that maleated polypropylene accelerates degradation during processing and deteriorates the properties of PP composites. Also, Paukszta et al. [44] have shown that modification of rapeseed straw with acetic anhydride gives the decrease in OIT and, in consequently, a negative effect on thermal stability of composites.

Nevertheless, some authors have not confirmed the negative role of lignocellulosic component and also compatibilization process in thermo-oxidative stability of the composites [46-48]. These authors noted completely different results. Ehsani et al. [46] noted that wood fibres increase the required time for oxidation of the composite in comparison to pure PP. Also, Bettini et al. [47] presented increase in OIT and initial decomposition temperatures when PP-g-MMA compatibilizer is incorporated into the polypropylene/coir composites. It is an indication that PPg-MA may act as antioxidant and thermal protective barrier for fibres. Moreover, Sapieha et al. [48] investigated the thermal degradation of polyethylene/cellulose composites and found that oxidation during processing resulted in enhanced adhesion between polymer and cellulose fibres.

Very little attention is paid to flammability of lignocellulosic filler/polypropylene composites [49-55]. Only a few papers [49, 52, 53] discuss the effect of the flame retardants on the flammability of wood/polymer composites. Yap et al. [49] studied the effects of phosphonates on the flame retarding properties of wood-polymer composites. Sain et al. [50] found that magnesium hydroxide can effectively reduce the flammability of natural fibre-filled polypropylene composites. Zhang et al. [53] investigated the effect of ammonium polyphosphate on the flame retarding characteristics of wood-fibre/polypropylene composites. Nayak et al. [54] noted that the composites with the sisal fibre showed lower burning rate than that of polypropylene matrix. Moreover, the burning rate of the sisal/PP composites compatibilized with MA-g-PP further reduced as compared to that of the uncompatibilized composites. Among the composites filled with treated fibres, the sisal fibre modified with silane compound/PP composites showed lowest rate of burning. Borysiak et al. [55] found that differences of melt flow index (MFI) among the polypropylenes strongly influence flammability characteristics of the composites. Polypropylene composites with higher MFI values have longer time to ignition, lower heat release rate (HRR) and longer total burning time.

In the present work, the research was realised in two directions. The first concerned the effects of modification of the lignocellulosic component on the thermo-oxidative stability of wood/PP composite. Up to now, the quantitative results on the variability of OIT as a function of chemical modification of lignocellulosic fillers have not been presented in literature. The second direction concerned the effects of the chemical treatment of wood filler on the flammability of composite materials. It should be emphasised that a rational approach to designing process of production of composite materials of lignocellulose materials and polymers needs analysis of such problems as thermal-oxidative stability and flammability of the lignocellulosic fillers/polymer composites. Moreover, a good knowledge of these parameters can lead to the use of a proper stabilisation system for the composite materials and consequently a longer life time in service.

\section{Experimental}

\section{Materials}

Polypropylene Moplen HP456 J supplied by LyondellBasell was used as matrix in the experiment. It was characterised as follows: isotactic content-95\%, melting 
temperature- $166^{\circ} \mathrm{C}$ and melt flow index $\left(\mathrm{MFI}_{230 \mathrm{C}}\right.$, $2.16 \mathrm{~kg})=2.4-3.2 \mathrm{~g} / 10 \mathrm{~min}$.

The pine wood (Pinus silvestris) was supplied by Forestry-Kaminska (Poland), which had particle size between 0.5 and $1.0 \mathrm{~mm}$. The wood filler was dried at $70{ }^{\circ} \mathrm{C}$ in an air-circulating oven for $24 \mathrm{~h}$ prior to use. The moisture content of the pine wood was less than 1 mass $\%$.

Chemical modification of wood

\section{Mercerisation}

The wood was treated at room temperature in the aqueous solution of sodium hydroxide with $17.5 \%$ (in mass) concentrations for $60 \mathrm{~min}$ with vigorous stirring. Afterwards, the alkalized wood was washed with distilled water for several times to remove the excess of $\mathrm{NaOH}$. Finally, the wood was dried in the air at an elevated temperature (ca. $110^{\circ} \mathrm{C}$ ), until constant weight was achieved.

\section{Esterification}

Part of the alkali-treated wood was immersed in a one molar solution of maleic anhydride in xylene and then heated at reflux temperature for $8 \mathrm{~h}$. Vigorous stirring of the slurry was achieved by the use of a mechanical stirrer at a rate of $100 \mathrm{rpm}$. When the time of the reaction expired, the slurry was filtered, the modified wood was washed several times with distilled water and extracted by the ethanol:toluene mixture $(2: 1, \mathrm{v} / \mathrm{v})$ in the Soxhlet apparatus for $8 \mathrm{~h}$ to eliminate the unreacted anhydride. Finally, the treated wood was dried in an oven at $80^{\circ} \mathrm{C}$ until its mass reached a constant value. The esterification process was confirmed by the FTIR spectra and mass percent gain $[56,57]$.

Preparation of wood-polypropylene composites

All composites samples were prepared by Fairex singlescrew extruder (Mc Nell Akron Repiquet, France). It has a screw diameter of $25 \mathrm{~mm}$ and a length-to-diameter ratio $\mathrm{L} / \mathrm{D}=25$. The screw speed was fixed at 25-30 rpm, while the cylinder temperatures were chosen as 140, 180, 195 and $190{ }^{\circ} \mathrm{C}$ from the hopper to the die. The extrudate was subsequently pelletized into granules and dried under vacuum at $80{ }^{\circ} \mathrm{C}$ for $24 \mathrm{~h}$ to remove any residual water. The product obtained contained $50 \%$ of pine wood.

In the second stage, the samples used for the OIT and flammability investigations were prepared using compression moulding. Pellets obtained from the extrusion process were compression moulded in order to obtain the boards (size $100 \times 100 \times 4 \mathrm{~mm}$ ). Compression moulding conditions were as follows: $5 \mathrm{~min}$ at $190{ }^{\circ} \mathrm{C}$ under 4 bar in order to eliminate the effects of their thermal history, cooling to $60{ }^{\circ} \mathrm{C}$ under pressure $(4 \mathrm{bar})$ at $10{ }^{\circ} \mathrm{C} \mathrm{min}^{-1}$.

Oxidation induction time (OIT)

DSC measurements were carried out in a DSC 821 calorimeter (Mettler Toledo). This analysis followed the conditions stated in ASTM D-3895-07. The uncovered sample pan (approximately $15 \mathrm{mg}$ ) together with an empty reference pan in DSC oven were heated at a heating rate of $20 \mathrm{~K} \mathrm{~min}^{-1}$ to the temperature of $200{ }^{\circ} \mathrm{C}$ at which the OIT value was determined. When the temperature reaches $200{ }^{\circ} \mathrm{C}$, samples were maintained for $3 \mathrm{~min}$. Afterwards, hold the samples under nitrogen purge at the first time an isothermal step of $3 \mathrm{~min}$, switched from the nitrogen to an oxygen purge (indicated as time $t_{1}$ ). The samples should be maintained under isothermal conditions with the oxygen purge until a significant oxidative exothermic response is obtained. Once a significant exothermic onset has been obtained, the experiment can be terminated. The onset of this oxidation signal corresponds to a time $t_{2}$. The OIT value can be determined as the time between $t_{1}$ and $t_{2}$ $[40,41]$, and thus as difference between time after stabilisation of the baseline and the time for the onset corresponding to the beginning of the exothermal peak. The flow of nitrogen and oxygen was be adjusted to $50 \mathrm{~mL} \mathrm{~min}^{-1}$ during the entire measuring procedure.

\section{Flammability}

The flammability tests were performed according to ISO 5660-1 standard procedures (cone calorimeter). All specimens of dimensions $100 \times 100 \times 4 \mathrm{~mm}$ were exposed horizontally to an external heat flux of $35 \mathrm{~kW} \mathrm{~m}^{-2}$. Several parameters were obtained from a cone calorimeter tests, such as time to sustained ignition (TTI), peak heat release rate $\left(H R R_{\max }\right)$, total heat released (THR), mass loss rate (MLR), heat of combustion (HOC), specific extinction area (SEA), $\mathrm{CO}$ and $\mathrm{CO}_{2}$ yields.

\section{Results and discussion}

\section{Oxidation induction time}

An interesting problem was to check the effect of chemical modification of wood on thermo-oxidative stability of composite materials in the melt states. The oxidation induction time (OIT) is evaluated in accordance with Fig. 1.

In this technique, the higher resistance to oxidation provides the high OIT value [58]. It can be observed from Fig. 1 that pine wood decreases the required time for 


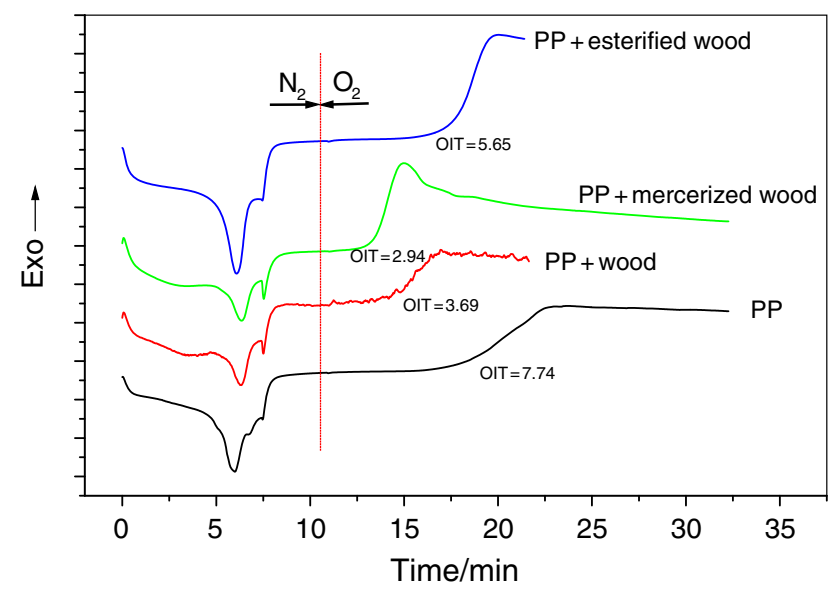

Fig. 1 Oxidation induction time (OIT) for polypropylene and composites

oxidation of the composites in comparison to polypropylene matrix $(\mathrm{OIT}=7.74 \mathrm{~min})$. As it can be seen, the untreated wood/PP composite has the OIT of $3.69 \mathrm{~min}$. Analysis of literature data has revealed many controversies. Our results are in the contrast to those of Paoli et al. [43], who observed that the curaua fibres do not influence the oxidative thermal stability of the composites in comparison with polymer matrix. However, Paukszta et al. [44] have found that rapeseed straw/PP composite showed a much lower OIT than the pure polypropylene.

This phenomenon may be explained by the increase of polar groups $(-\mathrm{OH})$ in composite material provided by the wood, which can lead to side reactions during cellulose decompositions. The presence of oxygen is another major factor for promoting degradation during processing, while polypropylene matrix is particularly susceptible to oxidative degradation during processing by the only presence of carbon-carbon chain bonds [59].

It is interesting that the alkali treatment decreases the OIT of composite to $2.94 \mathrm{~min}$. One explanation for this fact is that the alkalisation of wood is responsible for increased roughness of the lignocellulose filler as a result of removal of many low-molecular components [60-64] and fibrillation of the filler. Additionally, the effect of alkali on a lignocellulosic material is a swelling reaction, during which the natural crystalline structure of cellulose relaxes [65]. Consequently, the hydroxyl groups in wood are readily accessible. According to the result, addition of the cellulosic filler into the composite increased the formation of free radical and accelerated the decomposition process.

In general, the beneficial role of mercerisation is not only to remove fats and impurities from the surface of lignocellulose filler, but also to remove lignin and hemicelluloses. Due to its structure, lignin has been investigated as antioxidant $[47,66]$. The high thermal stability of lignin is due to the presence of complex phenylpropanoid units, which consist of aromatic phenyl groups. Gregorova et al. [66] presented increased antioxidant efficiency when lignin was added into polypropylene. Also, Bettini et al. [47] showed that incorporation of lignin in the polypropylene/ coir composites resulted in increase in both the initial thermal decomposition temperatures and oxidation induction time. In view of this and on the basis of our results, we can claim that content of lignin in the wood is closely related to the thermo-oxidative stability of composites. On the other hand, decrease in the amount of lignin (after mercerization) causes a decrease in the oxidation induction time.

Another explanation could be due to the polymorphism of cellulose. It is well known that the treatment of lignocellulose materials with alkaline chemical leads to conversion cellulose I into cellulose II and causes the decrystallisation of cellulose [65, 67]. According to literature data, the mercerisation of wood leads to a decrease in its nucleation abilities and prevented the formation of transcrystalline layer. According to these authors, transcrystallisation is a result of interactions between polypropylene and cellulose at the molecular level. In view of the above, the presence of transcrystalline structures can be vital for getting composites of desired properties [68]. Weak interphase interactions (lack transcrystalline structure) are responsible for the appearance of cracks and delamination of the composites [68], leading to accelerating oxidation of composites. Moreover, Huang et al. [69] have pointed out that the lower crystallinity of cotton after alkaline treatment results in the more readily degradable of cellulosic polymers. In previous work [33], we showed that the crystallinity for untreated wood is $59 \%$, whereas that for mercerised wood only $45 \%$. The present study indicates that the effect of the alkaline treatment is that of decreasing the OIT value, and in consequently, reducing the thermo-oxidative stability of the mercerised wood/PP composite.

Unexpectedly, esterified wood/PP composite showed higher values for the OIT than the untreated wood/PP and mercerised wood/PP composites. Esterification reaction was found to play a role in enhancing the oxidative stability of composite materials (OIT $=5.65 \mathrm{~min}$.). To the best of our knowledge, there are no reports on a relation between chemical modification of lignocellulosic fillers and thermooxidative stability of composite materials. Analysis of literature data has revealed some papers only $[43,44]$ and simultaneously many controversies. Our results are in contrast to the results described by Araujo et al. [43], who presented that the curaua fibres/polyethylene composites compatibilised with maleic anhydride grafted polyethylene are less stable in comparison with no compatibilised 
materials. Also, Paukszta et al. [44] showed that the modification of rapeseed straw with acetic anhydride gives the decrease in OIT and decrease in thermal stability of composites.

It is possible that improvement in the thermo-oxidative stability of such composites is a result of greater hydrophobicity of wood modified by maleic anhydride. The composites containing wood of lower content of hydroxyl groups are more resistant to thermal destruction processes. It should be emphasised that wood esterification is responsible for improvement of interphase adhesion between the modified filler and the polymer matrix. Consequently, additional interactions at the interphase can be responsible for increased resistance to thermo-oxidative reactions.

\section{Flammability}

The cone calorimeter based on the oxygen consumption has been used to evaluate the flammability characteristics of composites and polymer matrix. The heat release rate measured by cone calorimeter is a very important parameter as it expresses the intensity of fire [53, 70]. Moreover, the time to reach $\mathrm{HRR}_{\max }$ value provides information on the material contributing to the first stage of fire development. Other important parameters that help the understanding of the fire hazard related to materials are smoke generation (as specific extinction area, SEA) and emission of toxic gases ( $\mathrm{CO}$ accompanied by $\mathrm{CO}_{2}$ ). The changes of HRR as a function of burning time for different samples are shown in Fig. 2, and average values of the most important parameters are presented in Table 1.

Significant differences in reaction-to-fire parameters are observed between polypropylene matrix and composites. As follows from Fig. 2, the composites have shorter times

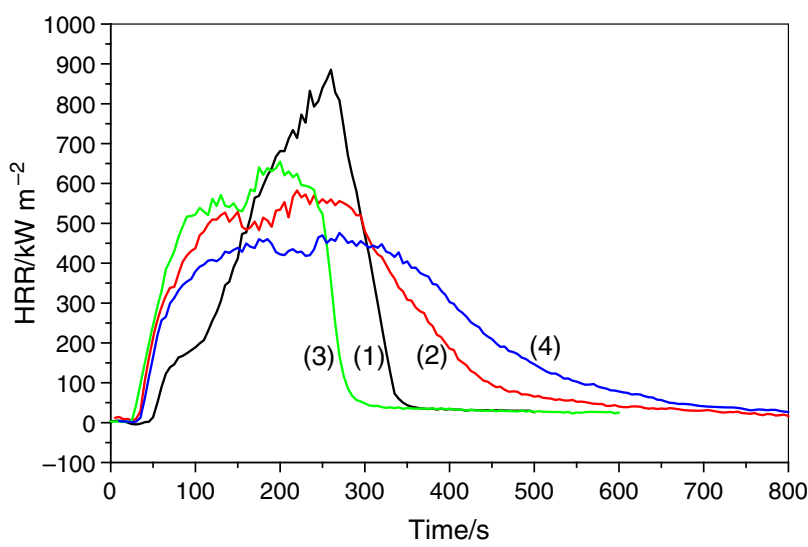

Fig. 2 Heat release rate versus burning time for polypropylene and composite materials: (1) PP, (2) PP + wood, (3) PP + mercerised wood, (4) PP + esterified wood to ignition than the unfilled polypropylene. Pure polypropylene after ignition burns quickly, and its combustion is characterised by a sharp HRR curve in the range of $50-260 \mathrm{~s}$. The heat released rate $\left(\mathrm{HRR}_{\max }\right)$ for polypropylene is $885 \mathrm{~kW} \mathrm{~m}^{-2}$. The combustion of this polymer is complete in about $350 \mathrm{~s}$. For composite materials, the shape of HRR curves is different and resembles that characteristic of lignocellulose materials. Each HRR curve presented in Fig. 2 has a characteristic minimum between two peaks. Such a bimodal shape of HRR curve for the composites indicates the possibility of char layer formation. The wood filler is responsible for carbonisation and damping of heat release rate at the first stage of combustion (the first peak in Fig. 2), and then as a result of char-surface cracking, the whole sample is combusted (the second peak in Fig. 2). The shape of HRR curves depends also on the type of composite. $\mathrm{HRR}_{\max }$ for the composites with untreated wood is $582 \mathrm{~kW} \mathrm{~m}^{-2}$ and is reached after $221 \mathrm{~s}$ of combustion. The wood modification with maleic anhydride causes a decrease in $\mathrm{HRR}_{\max }$ to a level of $475 \mathrm{~kW} \mathrm{~m}^{-2}$ after $270 \mathrm{~s}$, which corroborates the decrease in the combustion rate of such composites. Both types of composites, with unmodified and modified wood, have much longer times of complete combustion than pure polypropylene, which reach over $600 \mathrm{~s}$. The combustion behaviour of the composite with mercerised wood is completely different. Such a composite has poorer flammability as evidenced by higher $\operatorname{HRR}_{\max }\left(655 \mathrm{~kW} \mathrm{~m}^{-2}\right)$ and shorter time to reach $\mathrm{HRR}_{\max }$ peak (201 s) than the other composites. The composites of PP/mercerised wood, after reaching $\mathrm{HRR}_{\text {max }}$ peak, show a very short time of combustion completion, close to $300 \mathrm{~s}$.

According to Table 1, also the other parameters characterising flammability, THR, MLR, HOC and SEA, are considerably smaller for the composites than for the polypropylene matrix. Interestingly, the parameters decrease for the composites studied in the following sequence: PP/mercerised wood $>\mathrm{PP} /$ untreated wood $>\mathrm{PP} / \mathrm{esterified} \mathrm{wood.}$ This order is the same as that of HRR decrease and confirms that the wood modification with maleic anhydride is responsible for improvement in the flammability characteristics (i.e. a delay in combustion), while wood mercerisation causes its definite deterioration.

The toxicity of gas products of combustion of polypropylene and the composites was determined by emission of $\mathrm{CO}$ accompanied by $\mathrm{CO}_{2}$. The results given in Table 1 show that the combustion of the composites produces lower emission of $\mathrm{CO}$ and $\mathrm{CO}_{2}$ than the polypropylene matrix, and this emission is the lowest for the composites with esterified wood.

As follows from the result of the study, the flammability of composites is to the highest degree determined by the type of lignocellulose filler and also by the interphase 
Table 1 Average values of flammability parameters for polypropylene and composite materials

\begin{tabular}{|c|c|c|c|c|c|}
\hline \multirow[t]{2}{*}{ Parameter } & \multirow[t]{2}{*}{ Unit } & \multicolumn{4}{|c|}{ Material } \\
\hline & & PP & $\begin{array}{l}\mathrm{PP}+\text { untreated } \\
\text { wood }\end{array}$ & $\begin{array}{l}\mathrm{PP}+\text { mercerised } \\
\text { wood }\end{array}$ & $\begin{array}{l}\mathrm{PP}+\text { esterified } \\
\text { wood }\end{array}$ \\
\hline Time to ignition (TTI) & s & 50.6 & 35.7 & 30.6 & 41.2 \\
\hline Total heat released (THR) & $\mathrm{MJ} \mathrm{m}^{-2}$ & 200 & 166 & 182 & 156 \\
\hline Average mass loss rate (MLR) & $\mathrm{g} \mathrm{s}^{*} \mathrm{~m}^{-2}$ & 20.1 & 13.1 & 16 & 10.7 \\
\hline Peak HRR $\left(\mathrm{HRR}_{\max }\right)$ & $\mathrm{kW} \mathrm{m} \mathrm{m}^{-2}$ & 885 & 590 & 655 & 469 \\
\hline Time to reach HRR peak & $\mathrm{s}$ & 261 & 221 & 201 & 251 \\
\hline Average heat of combustion (HOC) & $\mathrm{MJ} \mathrm{kg}^{-1}$ & 40.8 & 36.4 & 38.3 & 34.6 \\
\hline $\begin{array}{l}\text { Average specific extinction area } \\
\text { (SEA) }\end{array}$ & $\mathrm{m}^{2} \mathrm{~kg}^{-1}$ & 459 & 334 & 388 & 271 \\
\hline Average CO yield & $\mathrm{kg} \mathrm{kg}^{-1}$ & 0.028 & 0.021 & 0.023 & 0.013 \\
\hline Average $\mathrm{CO}_{2}$ yield & $\mathrm{kg} \mathrm{kg}^{-1}$ & 2.99 & 2.37 & 2.47 & 2.21 \\
\hline
\end{tabular}

interactions between the polymer and the filler, which can be to some degree controlled by the chemical modification of the filler. Wood modification with maleic anhydride leads to improved interphase adhesion with polypropylene matrix [71] and to reduced combustion effectiveness (rate). This observation is fully consistent with the finding of other authors [72] according to which poor polymer-filler adhesion leads to increased combustion rate. Our very interesting observation was much poorer flammability characteristics of the composites with mercerised wood. It should be added that mercerisation can have a beneficial effect by increasing roughness of the lignocellulose filler as a result of removal of low-molecular components and the filler fibrillation [60-64, 73-76]. The increase in the wood roughness can be responsible for the increased rate of combustion of the composites with mercerised wood. Mercerisation leads to removal of lignin, which improves the interactions between the filler and the matrix. It is known [72] that poorer adhesion between the filler and the matrix may lead to deterioration of the flammability characteristics of composites, that is, to increased combustion rate. It should be mentioned that alkalisation of wood is also responsible for the formation of another polymorphous variety of cellulose, the so-called cellulose II, as reported in detail in [33, 34]. Cellulose II has much worse nucleating properties, which means that its presence hinders the formation of transcrystalline structures. Deterioration of the nucleating ability of the lignocellulose filler containing cellulose II weakens the polymer-filler interphase interactions, and thus has a negative influence on the characteristics of flammability of the composite materials.

To sum up, there is a good agreement between the results concerning the flammability of wood/polypropylene composites with those obtained in the thermo-oxidative stability determination. Results of the studies have revealed a very good correlation between the OIT and TTI parameters, which means that the flammability of the composites, measured as the time to sustained ignition, is closely related to their thermo-oxidative stability. The composites of high thermo-oxidative stability also show high resistance to inflammation. The composites with mercerised wood show the poorest flammability characteristics and the lowest resistance to thermo-oxidative processes. The opposite effects were observed for the composites with esterified wood, the increase in thermo-oxidative stability, increase in time to ignition and decrease in the combustion rate.

The studies presented in this paper are planned to be continued by testing the effects of different modifications of the lignocellulose fillers on the thermo-oxidative stability and flammability of the composite materials obtained. The effects of the cellulose and lignin isolated from the fillers on the above parameters will also be checked. The information gained from the studies is substantial when considering the use of these types of composites in industry.

\section{Conclusions}

The above-described studies of thermo-oxidative stability and flammability of composite materials have brought interesting conclusions. All composite materials studied showed oxidation induction time (OIT) shorter than that of the polypropylene matrix. Chemical modifications of wood fillers had a significant effect on OIT. The thermo-oxidative stability of the composites with mercerised wood was lower (shorter OIT) than that of the composite with unmodified wood. The modification of wood filler with maleic anhydride led to much higher OIT than that of the sample with unmodified wood, which is the evidence of improved thermo-oxidative stability.

The flammability tests on a cone calorimeter confirm the significant differences in the reaction-to-fire parameters between unfilled polypropylene and the composites. The latter shows lower values of $\mathrm{HRR}_{\max }$, time to reach $\mathrm{HRR}_{\text {max }}$ peak, time to ignition, THR, MLR and HOC than 
the corresponding values obtained for the polymer matrix. The wood modification with maleic anhydride brought a considerable improvement in the flammability characteristics, manifested by a much longer time of combustion completion and a lower heat release rate. Much poorer flammability characteristics was obtained for the composites with mercerised wood, as they showed higher $\mathrm{HRR}_{\max }$ and much shorter time of combustion completion than the composites with unmodified wood. Interestingly, all composites were characterised by lower emission of toxic gas products of combustion than polypropylene. Moreover, this paper provides the data that would help explain the mechanism of thermo-oxidative degradation of wood/PP composites taking into account molecular interaction of filler matrix (controlled by chemical modification of filler) and also polymorph varieties of lignocellulosic component.

Acknowledgements This research was supported by Grant of Poznan University of Technology 32-447/2015 DS-PB.

Open Access This article is distributed under the terms of the Creative Commons Attribution License which permits any use, distribution, and reproduction in any medium, provided the original author(s) and the source are credited.

\section{References}

1. Ku H, Wang H, Pattarachaiyakoop N, Trada M. A review on the tensile properties of natural fiber reinforced polymer composites. Compos Part B Eng. 2011;42:856-73.

2. Thakur VK, Thakur MK, Raghavan P, Kessler MR. Progress in green polymer composites from lignin for multifunctional applications: a review. ACS Sustain Chem Eng. 2014;2:1072-92.

3. Faruk O, Bledzki AK, Fink HP, Sain M. Biocomposites reinforced with natural fibers: 2000-2010. Prog Polym Sci. 2012;37:1552-96.

4. Koronis G, Silva A, Fontu M. Green composites: a review of adequate materials for automotive applications. Compos Part B Eng. 2013;44:120-7.

5. Kalia S, Kaith BS, Kaur I. Cellulose fibers: bio- and nano-polymer composites. Berlin: Springer; 2011.

6. Thakur VK, Singha AS, Thakur MK. Natural cellulosic polymers as potential reinforcement in composites: physicochemical and mechanical studies. Adv Polym Technol. 2013;32:427-45.

7. Xie Y, Hill CAS, Xiao Z, Militz H, Mai C. Silane coupling agents used for natural fiber/polymer composites: a review. Compos Part A App Sci Manuf. 2010;41:806-19.

8. Kalia S, Kaith BS, Kaur I. Pretreatments of natural fibers and their application as reinforcing material in polymer compositesa review. Polym Eng Sci. 2009;49:1253-72.

9. Zafeiropoulos NE, Williams DR, Baillie CA, Matthews FL. Engineering and characterization of the interface in flax fibre/polypropylene composite materials. Part I. Development and investigation of surface treatment. Compos Part A. 2002;33:1083-93.

10. Ashori A, Nourbakhsh A. Reinforced polypropylene composites: effects of chemical compositions and particle size. Bioresour Technol. 2010;101:2515-9.

11. Dominkovics Z, Danyadi L, Pukanszky B. Surface modification of wood flour and its effect on the properties of PP/wood composites. Compos Part A. 2007;38:1893-901.
12. Kumar Thakur V, Kumari Thakur M, Kumar Gupta R. Review: raw natural fiber-based polymer composites. Int J Polym Anal Charact. 2014;19(3):256-71.

13. Oksman K, Clemons C. Mechanical properties polypropylenewood and morphology of impact modified flour composites. J Appl Polym Sci. 1998;67:1503-13.

14. Thakur VK, Singha AS, Thakur MK. Biopolymers based green composites: mechanical, thermal and physic-chemical characterization. J Polym Environ. 2012;20:412-21.

15. Hill CAS. Wood modification: chemical, thermal and other processes. Chicheste: Wiley; 2006.

16. Rowell RM. Encyclopedia of forest sciences. In: Burley J, Evans J, Youngquist J, editors. Oxford: Elsevier Academic Press: The Boulevard, Lanford Lane Kidlington; 2004. pp 1269-1274.

17. Borysiak S. Fundamental studies on lignocellulose/polypropylene composites: effects of wood treatment on the transcrystalline morphology and mechanical properties. J Appl Polym Sci. 2012;127:1309-22.

18. Mahlberg R, Paajanen L, Nurmi A, Kivisto A, Koskela K, Rowell RM. Effect of chemical modification of wood on the mechanical and adhesion properties of wood/fiber/polypropylene fiber and polypropylene/veneer composites. Holz als Roh- Und Werkstoff. 2001;59:319-26.

19. Thakur VK, Thakur MK, Gupta RK. Development of functionalized cellulosic biopolymers by graft copolymerization. Int $\mathrm{J}$ Biol Macromol. 2013;62:44-51.

20. Thakur VK, Thakur MK, Gupta RK. Graft copolymers of natural fibers for green composites. Carbohydrate Polym. 2014;104: 87-93.

21. Thakur VK, Thakur MK, Gupta RK. Synthesis of lignocellulosic polymer with improved chemical resistance through free radical polymerization. Int J Biol Macromol. 2013;61:121-6.

22. Thakur VK, Thakur MK, Gupta RK. Rapid synthesis of graft copolymers from natural cellulose fibers. Carbohydr Polym. 2013;98:820-8.

23. Thakur VK, Thakur MK, Gupta RK. Graft copolymers from cellulose: synthesis, characterization and evaluation. Carbohydr Polym. 2013;97:18-25.

24. Thakur VK, Vennerberg D, Kessler MR. Green aqueous surface modification of polypropylene for novel polymer nanocomposites. ACS Appl Mater Interfaces. 2014;6:9349-56.

25. Quillin DT, Caulfield DF, Koutsky JA. Crystallinity in the polypropylene/cellulose system. I. Nucleation and crystalline morphology. J Appl Polym Sci. 1993;50:1187-94.

26. Amash A, Zugenmaier P. Morphology and properties of isotropic and oriented samples of cellulose fibre-polypropylene composites. Polymer. 2000;41:1589-96.

27. Lenes M, Gregersen OW. Effect of surface chemistry and topography of sulphite fibres on the transcrystallinity of polypropylene. Cellulose. 2006;13:345-55.

28. Arbelaiz A, Fernandez B, Ramos JA, Mondragon I. Thermal and crystallization studies of short flax fibre reinforced polypropylene matrix composites: effect of treatments. Thermochim Acta. 2006;440:111-21.

29. Lee BG, Lee S, Via BK. Influence of surface morphology of the kraft pulp fibers on the growth of the transcrystalline layer of polypropylene. J Appl Polym Sci. 2010;116:1958-66.

30. Borysiak S. Determination of nucleation ability of wood for nonisothermal crystallisation of polypropylene. J Therm Anal Calorim. 2007;88:455-62.

31. Joseph PV, Joseph K, Thomas S, et al. The thermal and crystallisation studies of short sisal fibre reinforced polypropylene composites. Compos Part A. 2003;34:253-66.

32. Zafeiropoulos NE, Baillie CA, Matthews FL. A study of transcrystallinity and its effect on the interface in flax fibre reinforced composite materials. Compos Part A. 2001;32:525-43. 
33. Borysiak S. Influence of cellulose polymorphs on the polypropylene crystallization. J Therm Anal Calorim. 2013;113:281-9.

34. Borysiak S, Doczekalska B. X-ray diffraction study of pine wood treated with NaOH. Fibres Text East Eur. 2005;13:87-9.

35. Borysiak S. Influence of wood mercerization on the crystallization of polypropylene in wood/PP composites. J Therm Anal Calorim. 2012;109:595-603.

36. Abu-Sharkh BF, Hamid H. Degradation study of date palm fibre/ polypropylene composites in natural and artificial weathering: mechanical and thermal analysis. Polym Degrad Stab. 2004;85: 967-73.

37. Clemons CM. Wood-plastic composites in the Unites States: the interfacing of two industries. Forest Prod J. 2002;52:10-8.

38. Lei Y, Wu Q, Clemons CM, Yao F, Xu Y. Influence of nanoclay on property of HDPE/wood composites. J Appl Polym Sci. 2007;106:3958-66.

39. Maldas D, Kokta BV. Influence of coupling agents and treatments on the mechanical properties of cellulose fiber-polystyrene composites. J Appl Polym Sci. 1989;37:751-75.

40. Peltzer M, Jimenez A. Determination of oxidation parameters by DSC for polypropylene stabilized with hydroxytyrosol (3,4-dihydroxy-phenylethanol). J Therm Anal Calorim. 2009;96:243-8.

41. Schmid M, Affolter S. Interlaboratory tests on polymers by differential scanning calorimetry (DSC): determination and comparison of oxidation induction time (OIT) and oxidation induction temperature (OIT*). Polym Test. 2003;22:419-28.

42. Pospisil J, Horak Z, Pilar J, Billingham NC, Zweifel H, Nespurek $\mathrm{S}$. Influence of testing conditions on the performance and durability of polymer stabilisers in thermal oxidation. Polym Degrad Stab. 2003;82:145-62.

43. Araujo JR, Waldman WR, De Paoli MA. Thermal properties of high density polyethylene composites with natural fibres: Coupling agent effect. Polym Degrad Stabilit. 2008;93:1770-5.

44. Paukszta D, Drzewiecka R. Badania czasu indukcji utleniania kompozytów polipropylenu napełnionego rozdrobnioną słomą rzepakową. Przemysł Chemiczny. 2012;91:1000-3.

45. Dominkovics Z, Hari J, Fekete E, Pukanszky B. Thermo-oxidative stability of polypropylene/layered silicate nanocomposites. Polym Degrad Stab. 2011;96:581-7.

46. Farhadinejad Z, Ehsani M, Khosravian B, Ebrahimi G. Study of thermal properties of wood plastic composite reinforced with cellulose micro fibril and nano inorganic fiber filler. Eur J Wood Prod. 2012;70:823-8.

47. Morandim-Giannetti AA, Agnelli JAM, Lancas BZ, Magnabosco R, Casarin SA, Bettini SHP. Lignin as additive in polypropylene/ coir composites: thermal, mechanical and morphological properties. Carbohydr Polym. 2012;87:2563-8.

48. Sapieha S, Pupo JF, Schreiber HP. Thermal degradation of cellulose-containing composites during processing. J Appl Polym Sci. 1989;37:233-40.

49. Yap MGS, Que YT, Chia LHL, Chan HSO. Thermal properties of tropical wood-polymer composites. J Appl Polym Sci. 1991;43: 2057-65.

50. Sain M, Park SH, Suhara F, Law S. Flame retardant and mechanical properties of nature fiber-PP composites containing magnesium hydroxide. Polym Degrad Stabilit. 2004;83:362-7.

51. Anna P, Zimonyi E, Mariton A, Matko S, Keszi S, Bertlan G. Surface treated cellulose fibres in flame retarded PP composites. Macromol Symp. 2003;202:245-54.

52 . Li B, He J. Investigation the mechanical property, flame retardancy and thermal degradation of LLDPE-wood fiber composite. Polym Degrad Stabilt. 2004;83:241-6.

53. Zhang ZX, Zhang J, Lu BX, Xin ZX, Kang CK, Kim JK. Effect of flame retardants on mechanical properties, flammability and foamability of PP/wood composites. Comp Part A. 2012;43: $150-8$.
54. Nayak SK, Dixit G, Appukuttan KK. Sisal fiber (SF) reinforced recycled polypropylene (RPP) composites. Int J Plast Technol. 2012;16:150-65.

55. Borysiak S. Flammability of wood-polypropylene composites. Polym Degrad Stab. 2006;91:3339-43.

56. Borysiak S. The supermolecular structure of polypropylene/wood composites. I) The influence of processing parameters and chemical treatment of filler. Polym Bull. 2010;64:275-90.

57. Borysiak S, Doczekalska B. The influence of chemical modification of wood on the nucleation ability of polypropylene composites. Polimery. 2009;54:820-7.

58. Gao X, Meng X, Wang H, Wen B, Ding Y, Zhang S, Yang M. Antioxidant behavior of a nanosilica-immobilized antioxidant in polypropylene. J Polym Degrad Stab. 2008;93:1467-71.

59. Mauri MC, De Stefano D, Di Meglio P, Irace C, Savarese M, Sacchi R, Cinelli MP, Carnuccio R. Hydroxytyrosol, a phenolic compound from virgin olive oil, prevents macrophage activation. Naunyn-Schmiedeberg's Arch Pharmacol. 2005;371:457.

60. Gwon JG, Lee SY, Chun SJ, Doh GH, Kim JH. Effect of chemical treatments of wood fibers on the physical strength of polypropylene based composites. Korean J Chem Eng. 2010;27: $651-7$.

61. Joseph PV, Kuruvilla J, Sabu T. Effect of processing variables on the mechanical properties of sisal-fiber-reinforced polypropylene composites. Compos Sci Technol. 1999;59:1625-40.

62. Marcovich NE, Aranguren MI, Reboredo MM. Modified woodflour as thermoset fillers. Part I. Effect of the chemical modification and percentage of filler on the mechanical properties. Polymer. 2001;42:815-25.

63. Albano C, Ichazo M, Gonzalez J, Delgado M, Poleo R. Effects of filler treatments on the mechanical and morphological behavior of $\mathrm{PP}+$ wood flour and $\mathrm{PP}+$ sisal fiber. Mat Res Innovat. 2001;4:284-93.

64. Kaith BS, Singha AS, Kumar S, Kalia S. Mercerization of flax fiber improves the mechanical properties of fiber reinforced composites. Int J Polym Mater. 2008;57:54-72.

65. Weyenberg I, Truong TC, Vangrimde B, Verpoest I. Improving the properties of UD flax fibre reinforced composites by applying an alkaline fibre treatment. Compos Part A. 2006;37:1368-76.

66. Gregorova A, Cibulkova Z, Kosikova B, Simon P. Stabilization effect of lignin in polypropylene and recycled polypropylene. Polym Degrad Stab. 2005;89:553-8.

67. Wertz JL, Bedue O, Mercier JP. Cellulose science and technology. Boca Raton: Taylor and Francis Group; 2010.

68. Nuriel H, Klein N, Marom G. The effect of the transcrystalline layer on the mechanical properties in the fibre direction of composite materials. Compos Sci Technol. 1999;59:1685-90.

69. Huang MR, Li XG. Thermal degradation of cellulose and cellulose esters. J Appl Polym Sci. 1998;68:293-304.

70. Babrauskas V. Describing product fire performance-manufacturers versus modelers needs. Fire Mater. 1994;18:289-96.

71. Borysiak S, Doczekalska B. Influence of chemical modification of wood on the crystallisation of polypropylene. Holz RohWerkst. 2006;64:451-4.

72. Horrocks AR, Priece D. Fire retardant materials. Cambridge: Woodhead Publishing Limited; 2001.

73. Mwaikambo LY, Ansell M. Chemical modification of hemp, sisal, jute and kapok fibers by alkalization. J Appl Polym Sci. 2002;84:2222-34.

74. Hon DNS. Chemical modification of lignocellulosic materials. New York, Basel, Hong Kong: Marcel Dekker; 1996.

75. Bledzki AK, Gassan J. Composites reinforced with cellulose based fibres. Progr Polym Sci. 1999;24:221-74.

76. Wang HM, et al. Removing pectin and lignin during chemical processing of hemp for textile applications. Textile Res J. 2003;73:664-9. 